\title{
Analysis and optimization of hybrid double lap aluminum-GFRP joints
}

\author{
G. Di Franco, B. Zuccarello* \\ Dipartimento di Ingegneria Chimica, Gestionale, Informatica, Meccanica, University of Palermo, Viale delle Scienze, 90128 Palermo, Italy
}

\section{A R T I C L E I N F O}

Article history:

Available online 7 June 2014

\section{Keywords:}

Hybrid joints

Bolting

Bonding

Fatigue

\begin{abstract}
A B S T R A C T
In this paper a systematic investigation of the mechanical performance of hybrid double-lap Al-GFRP bonded-bolted joints, has been carried out by using experimental analyses and numerical simulations. In order to detect the optimal geometric configuration, as well as to highlight the contribution of adhesive and bolts, the results relative to hybrid joints have been compared with those of simply adhesively bonded and simply bolted joints. The experimental and numerical results have shown that by using the minimum overlap length provided from theory, the bolt leads to a significant decreasing of both the maximum shear and the maximum peel stresses in the adhesive layer and, consequently, the hybrid joint exhibits a static tensile strength that is in practice equal to the sum of the relative values corresponding to the simply bonded joint and the simply bolted joint. Moreover, the so configured hybrid joint, exhibits an energy absorption and a fatigue strength higher than twice those of the simply adhesively bonded joint that are, in turn, higher than those of the simply bolted joint.
\end{abstract}

(c) 2014 Elsevier Ltd. All rights reserved.

\section{Introduction}

The modern use of Polymer Matrix Composites (PMCs) for the manufacturing of mechanical components requires the application of reliable joints between composite materials (usually reinforced with glass, carbon or aramid fibers) and the traditional materials (aluminum, steel, titanium, etc.) nowadays still widely-used to the primary structures of machines and mechanical systems. Usually, such structural junctions between composite and metal are made by using adhesively bonded joints or classical mechanical (bolted, riveted etc.) joints.

As it is well known, the main advantages of the mechanical joints are no thickness limitations, simple joint configuration, simple manufacturing process, simple inspection procedure, no environmental sensitivity, whereas the main drawbacks are due to the significant stress concentration around the hole, that leads to a decrease of the static and fatigue strength, as well as the possible damage of the composite due to the hole drilling procedure (micro and macro localized damage), that can compromise the structural integrity of the joint. Taking into account this drawbacks as well as the specific properties of the PMCS [1], it follows that the use of the bolted joints and welding (only for thermoplastic matrixes) are in general not advisable [2,3] whereas, due to their advantages as high stiffness, good fatigue properties, lightweightness and small stress concentration in adherents, the adhesive bonding is in

\footnotetext{
* Corresponding author. Tel.: +39 9123897286; fax: +39 916118277.

E-mail address: bernardo.zuccarello@unipa.it (B. Zuccarello).
}

general the technique that allows the user to obtain the best efficiency [4-7] for metal-composite or composite-composite joints. Unfortunately, the adhesively bonded joints are also affected by various drawbacks as the decay of the mechanical properties especially in presence of moisture, corrosive agents and/or working temperatures higher than room temperature.

In order to combine the advantages of the two joints techniques, in the last years Hybrid Bolted-Bonded (HBB) joints, obtained by combining a classical mechanical fastening (bolting) and a classical adhesively bonded (or co-cured) joint, have attracted great interest in various industrial field and, consequently in the research field [3,8-10].

Although several research works are reported in literature, nowadays there is not a sufficient knowledge of the mechanical properties of hybrid joints, and there are not methods at disposal of the designer for a reliable joint behavior prediction. In fact, hybrid joints have been often considered in literature only for repairing and/or to improving the damage tolerance. As an example, by a theoretical study on hybrid bonded/bolted joints between CFRP and titanium, Hart-Smith [11,12] has shown that, although no significant strength increment is observed respect to simply adhesively bonded joints (at room temperature the $98 \%$ of the applied load is transferred by the adhesive), the hybrid joints exhibit various benefits in repairing of bonded joints due to significant limitation of the damage propagation.

In [13] Fu and Mallick have studied the static and fatigue behavior of hybrid single-lap joints (bolted/bonded); in detail, by an experimental investigation on the effects of different configuration 
of washers, the authors observed that the performance of such hybrid joints depends significantly on the shape of the washer that influences the initial stress distributions due to the bolt tightening. Therefore, proper washer shapes that give a sufficient lateral clamping can significantly improve the joint performance.

Also, in [3] Jin-Hwe Kweonet et al. studied the effect of bolting on the static strength of an adhesively bonded Al-CFRP double lap joint; in particular, two different adhesives (film and paste types) and three types of joints (adhesive bonding, bolt fastening and adhesive-bolt hybrid) were considered. For the geometrical joint configuration considered, the authors observed that the strength of hybrid joints improves only when the strength of the mechanical joint is stronger than that of the simple adhesively bonded joint.

Moreover, in [8] Gordon Kelly has studied the load transfer in a single-lap Al-GFRP bolted-bonded joint, using a 3D finite element model that considers the influence of the contact between hole and bolt and the non-linear behavior of the coupled materials. By comparing the numerical results with those obtained experimentally by means of a special bolt instrumented with an electric strain gauge, it has been observed that the load transferred by the bolt increases with the thickness of the adhesive and of the adherents; on the contrary, it decreases with the increasing of both the overlap length and the elastic modulus of the adhesive.

Finally, in [14] Solmaz and Topkaya have studied the failure mechanism of adhesively, riveted and hybrid double-lap joints between GFRP elements; they predict the failure mechanism and the corresponding static tensile strength by using proper numerical simulations and approximate criteria, then they found that the strength of the studied hybrid joints is only slight higher than that of the simply riveted joint (about $+14 \%$ ).

Taking into account the above mentioned research works, as well as other works reported in literature here not cited for brevity sake, in order to give a further contribution to the knowledge of the mechanical performance of HBB joints between composite and metal, in the present paper systematic static and fatigue analyses were carried out by varying the main influence parameters, as the overlap length and the bolt tightening. In particular, a joint between an unidirectional glass-epoxy fiber reinforced plastics (GFRP) and an aluminum alloy type 2024T6, has been studied experimentally and numerically also by comparing its behavior with those of simple bonded and simple bolted joints.

\section{Experimental analyses}

The experimental analyses have been carried out by considering a HBB double-lap joint with internal adherent made by a GFRP unidirectional laminate (type $\left[0_{16}\right]$ ) having a total thickness $t_{\text {GFRP }}=4 \mathrm{~mm}$, and external adherents made by a plate of aluminum alloy (type $\mathrm{Al}$ 2024-T6) having thickness $t_{A l}=1.2 \mathrm{~mm}$ (see Fig. 1). The adherents thickness have been selected properly to obtain an approximately balanced joint [6,15-18], i.e. a joint in which the stiffness of the internal adherent is almost equal to that of the external adherents $\left(E_{L}{ }^{*} t_{c} \approx 2 E_{A l}{ }^{*} t_{A l}\right.$ - see also Fig. 1$)$. In practice, the actual properties of the coupled material gave a joint with a little unbalance of about $3 \%$, being the GFRP slight less stiff of the external adherents. Also, choosing the width of the specimens in accordance with the ASTM D3528 [19], the diameter of the bolt and its position (centered) have been selected so as to ensure a sufficient strength against the two basic mode of failure, i.e. net-tension mode and shearout mode [14].

In more detail, the GFRP internal adherent was made by hand lay-up and vacuum bagging, using a quite brittle epoxy resin (type SX-10) having shear modulus $G_{a}=1.1 \mathrm{GPa}$, Poisson ratio $v_{a}=0.4$, tensile strength $\sigma_{u, a}=60.0 \mathrm{MPa}$ and shear strength $\tau_{u, a}=46.0 \mathrm{MPa}$

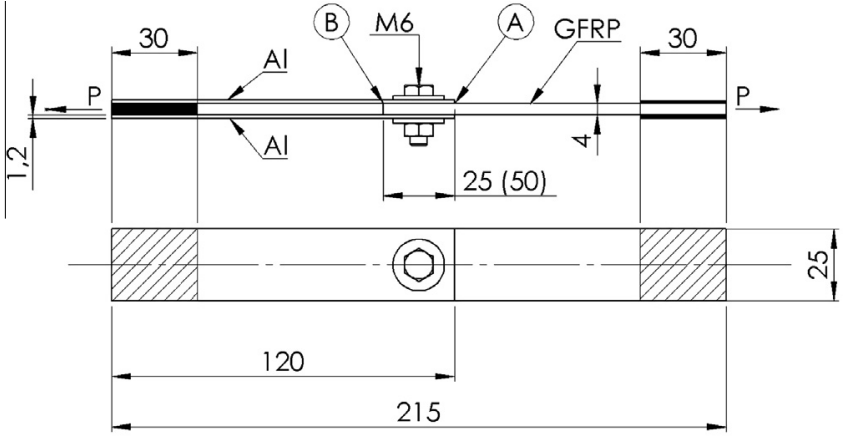

Fig. 1. Geometric configuration of the double lap joint analyzed.

[20]. In accordance with the results shown in literature for brittle adhesive (see as an example Ref. [21]), when SX-10 epoxy resin is used as adhesive in co-cured joints, then the damaging process of the joint follows always the nucleation and the successive propagation of a crack inner the adhesive (or at the adherent-adhesive interface if the relative adhesion is weaker [22]), until catastrophic failure.

The mechanical properties of the GFRP adherent were evaluated accurately through tensile tests performed in accordance with the ASTM standards $[23,24]$, and the following values were obtained: $E_{L}=39.5 \mathrm{GPa}, E_{T}=7.3 \mathrm{GPa}, G_{L T}=3.9 \mathrm{GPa}, v_{L T}=0.336, \sigma_{u, L}=552.0-$ $\mathrm{MPa}, \sigma_{u, T}=51.0 \mathrm{MPa}, \tau_{u, L T}=41.0 \mathrm{MPa}$. As it is well know, both the transverse tensile strength $\left(\sigma_{u, T}\right)$ and the shear strength $\left(\tau_{u, L T}\right)$ of the composite are lower than that of the adhesive (matrix) so that the transversal failure of the composite can become the cause of the failure of bonded joints [25].

The mechanical characteristics of the aluminum adherents, obtained by proper tensile tests [26] are instead: $E_{A l}=67.6 \mathrm{GPa}$, $\sigma_{y, A l}=140.0 \mathrm{MPa}$ e $\sigma_{u, A l}=252.6 \mathrm{MPa}$.

The bonding of the adherents is obtained by the well know "cocuring" procedure in which the adhesive is constituted by the same matrix of the composite; to this end, after the hand-lay up the laminate has been interposed between the external adherents with a sufficient compression, prior that the polymerization of the matrix is completed. To improve performance of the adhesively bonding, the aluminum surfaces to be bonded have been preliminary subjected to a unidirectional abrasion by using a grade P60 emery cloth, then to a successive proper cleaning with acetone. The direct observation of various transversal sections by a common microscope have shown that the co-curing procedure leads to an actual adhesive thickness $\eta \approx 0.1 \mathrm{~mm}$. After the bonding process has been completed by a curing at room temperature, the bolting has been obtained by drilling a centered hole and inserting a M6 hexagon head UNI 5727 bolt (having length of $20 \mathrm{~mm}$ ), with a standard washer having external diameter of $18 \mathrm{~mm}$ and thickness of $1.5 \mathrm{~mm}$. Also, at the two ends of the joint proper tabs have been bonded (see black elements in Fig. 1) to allow the correct positioning of the joint into of the test machine.

Concerning the overlap length, instead, various values included in the range $20-75 \mathrm{~mm}$, have been considered although detailed analyses have been carried out on joints having overlap length equal to 25 and $50 \mathrm{~mm}$; in practice such particular values correspond respectively to $l_{\min }$ and $2 l_{\min }$, being $l_{\min }$ the overlap length predicted by the theory $[6,15-18]$ through the following formula:

$l_{\text {min }}=\frac{7.5}{\beta}$

being $\beta$ the characteristic parameter that governs the shear stress concentration near the free edges, that for low shear stiffness materials (composites) is given by $[6,15-18]$ : 
$\beta=\sqrt{\frac{G_{a}}{\eta} \cdot\left(\frac{2}{E_{L} \cdot t_{c}}+\frac{1}{E_{A l} \cdot t_{A l}}\right)} / \sqrt{1+\frac{G_{a}}{\eta} \cdot\left(\frac{t_{c}}{6 G_{L T}}+\frac{t_{A l}}{3 E_{A l}}\right)} \approx 0.3$

As it can be shown by the theory [6,15-18], for brittle adhesive the increasing of the overlap length above $l_{\min }$ does not lead to the decreasing of the maximum stresses near the free edges (point $\mathrm{A}$ and B in Fig. 1), so that the tensile strength remain practically constant; on the contrary, the tensile strength of a simply bonded joint decreases abruptly if the overlap length decreases under the $l_{\min }$ value, because the reduction of the bonded surface and the significance increasing of the maximum stresses in the adhesive.

The overlap length of $50 \mathrm{~mm}$, i.e. of $2 l_{\mathrm{min}}$, represents in practice the value commonly used in various industrial fields (aeronautics, aerospace etc.) to compensate the decay of the reliability of simply adhesively bonded joints [15-18], especially in presence of adhesive creep and unavoidable manufacturing bonding defects [17], as well as of critical environmental conditions (moisture, high temperature etc.); however, in some practical applications higher overlap lengths are also used, although these values do not correspond to significant improvements of the failure load, that remains almost constant.

The overlap length value equal to $25 \mathrm{~mm}$, i.e. to $l_{\min }$, instead, has been properly selected to highlight how, unlike the common overlap lengths of $2 l_{\min }$ or higher, it permits to maximize the beneficial compression effects of the bolt that lead to a significant decrease of the maximum stresses which develop at the free edges of the adhesive layer of the simply bonded joint [15-18], with a consequent significant increase of the mechanical performance of the HBB joint with respect to those of the simply bonded joint.

\subsection{Static tests}

The static tests on the above described Al-GFRP joints were performed by using a hydraulic materials testing machine MTS 810 , equipped by a $100 \mathrm{kN}$ load cell (Fig. 2). In accordance with the relative ASTM standard [19], all the experimental tests were carried out under displacement control with a speed of $1.2 \mathrm{~mm} / \mathrm{min}$. For each joint configuration 5 specimens have been tested.

In order to monitor the failure modes, the analyzed joints have been observed by using a HD digital camera type Canon 5D with a frequency of $5 \mathrm{~Hz}$.

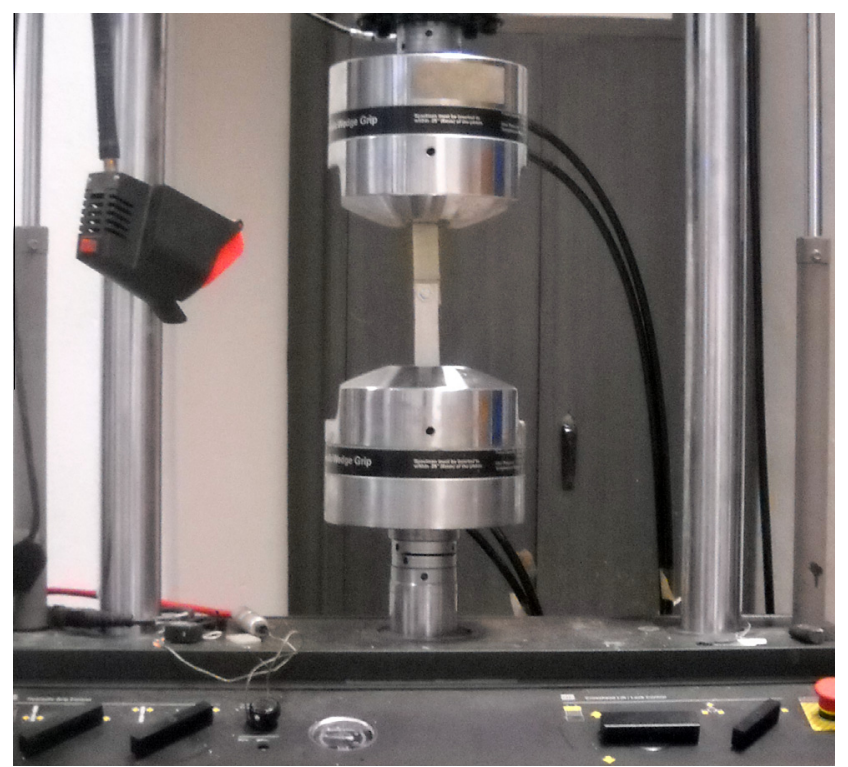

Fig. 2. Test machine and experimental layout used to tensile tests.

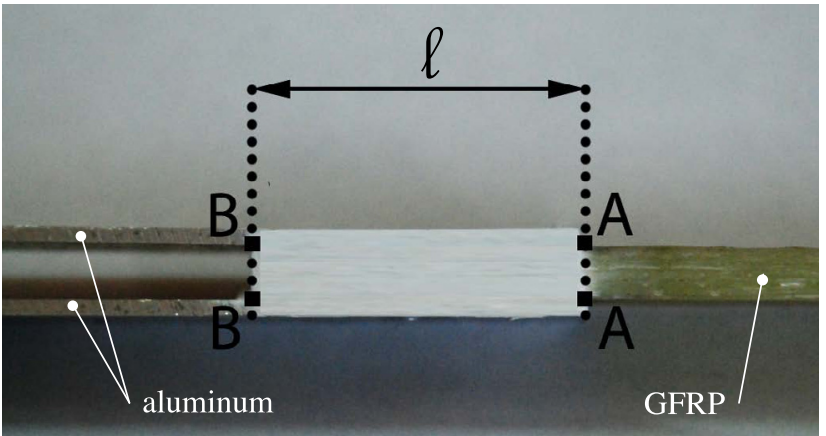

Fig. 3. Image of the simply bonded joint with lateral surface tinted with white paint.

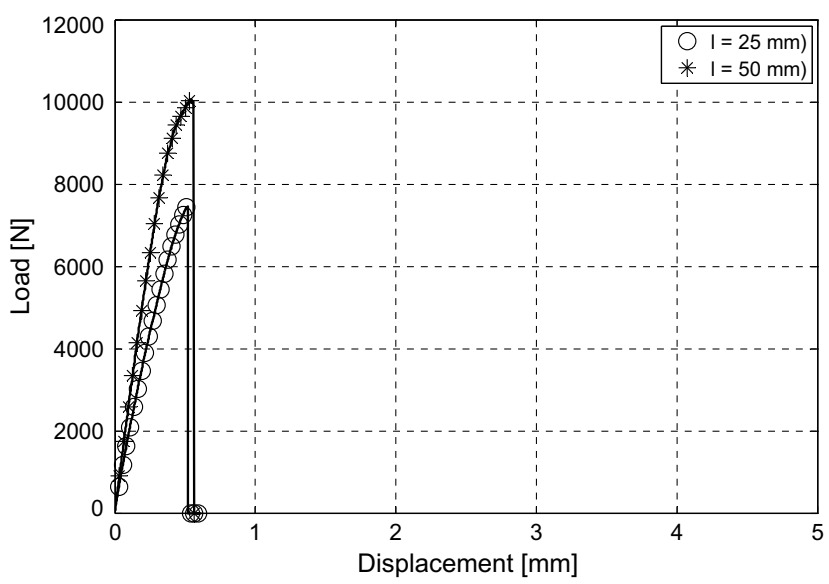

(a)

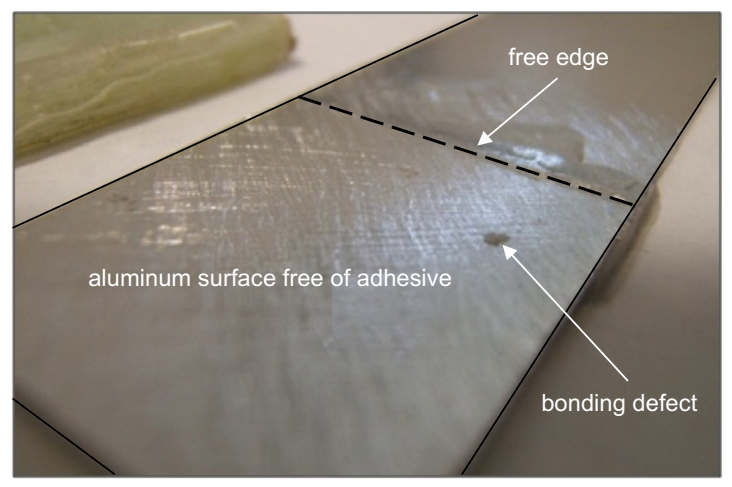

(b)

Fig. 4. (a) Load-displacement curves for the simply adhesively bonded joints and (b) typical image of the surface of the aluminum adherent after adhesive failure.

The experimental study has initially focused on the analysis of the tensile strength and of the failure modes of the various joint configurations considered. First, the simply adhesively bonded and the simply bolted joints have been analyzed, then the HBB joints have been tested.

\subsubsection{Simply adhesively bonded joints}

In order to detect the start point of the failure and the successive failure propagation path, the lateral surfaces of the overlap zone of the specimens, were tinted with a white brittle paint (Fig. 3). 


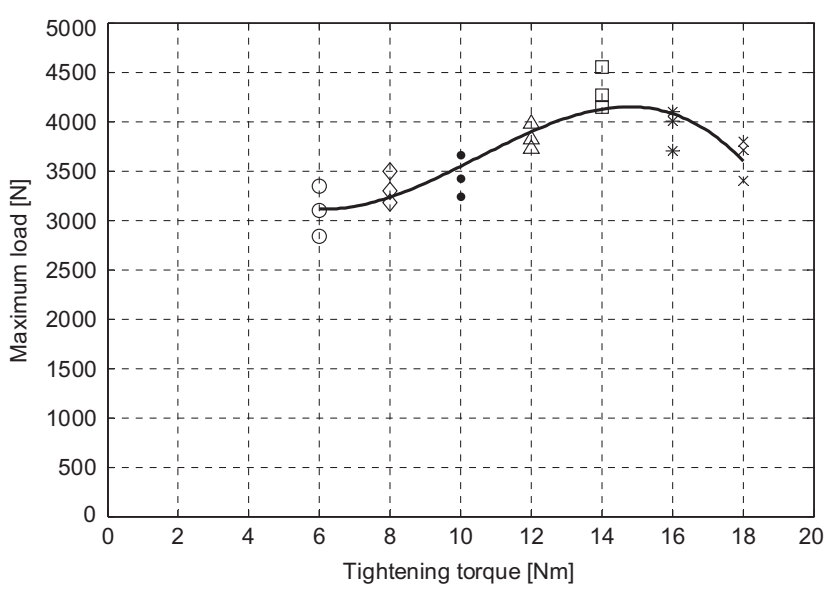

Fig. 5. Simple bolted joints: maximum load vs. bolt tightening torque.

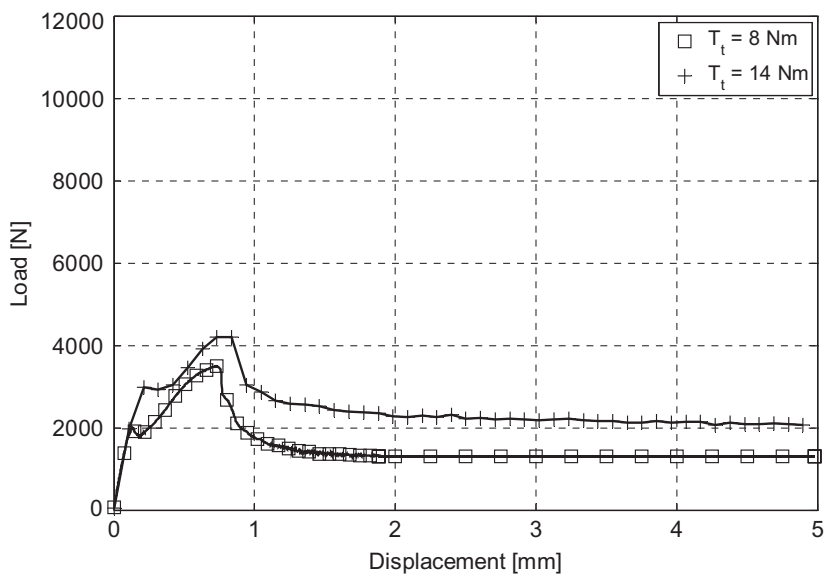

Fig. 6. Load-displacement curves for bolted joints, with various tightening torque values.

Fig. 4(a) shows the typical load-displacement curves for the simply adhesively bonded joints having overlap length of 25 and $50 \mathrm{~mm}$. The represented load is the total load applied to the examined joint, whereas the displacement is that of the crossbar of the test machine.

In detail, from Fig. 4 it is possible to observe how the simply adhesively bonded joints exhibit in practice a linear load-displacement relationship up to failure (brittle behavior), that occurs at the interface between adhesive and aluminum, as it is possible to observe in Fig. 4(b) that shown the surface of the aluminum adherent after failure; it is seen how such a surface is in practice free of adhesive except very little portions due to unavoidable bonding defects. Also, in accordance with the theory [6,15-18], the experimental evidence has shown that the adhesive failure starts from the attach edge of the less stiff adherent, i.e. of the GFRP adherent (point A in Fig. 3), where the maximum shear stress and the maximum peel stresses develop; successively, it propagates abruptly up to the attach edge of the aluminum adherents (point B in Fig. 3).

In particular, Fig. 4(a) shows that the joint with overlap length $l=25 \mathrm{~mm}$ has an average maximum tensile load $P_{\max }=7295 \mathrm{~N}$ and an energy absorption $E_{a}=1.99 \mathrm{~J}$, whereas the joint with overlap length $l=50 \mathrm{~mm}$ has higher mechanical performance with $P_{\max }=9862 \mathrm{~N}(+35 \%)$ and $E_{a}=3.62 \mathrm{~J}(+82 \%)$. Although the load-carrying capacity is not proportional to the overlap length, as occurs for a ductile adhesive [27], in accordance with Ref. [17] such a result confirms how for a brittle adhesive the increasing of the overlap length over $l_{\min }$ can lead to non negligible increases of the failure load due to (a) the decreasing of the mean shear stress along the overlap, that leads to a reduction of the creep and of the effect of unavoidable internal defects of the bonding, and (b) the increasing of the stress gradient at the free edges that leads to the increasing of the actual adhesive strength (sensitivity of the adhesive to the stress gradient).

\subsubsection{Simply bolted joints}

Preliminary tensile tests have shown that the tensile strength of the examined bolted joint does not depend on the particular overlap length if this is higher than the corresponding minimum value. Therefore, although all the tensile tests reported in the following have been performed on bolted joints having $l=25 \mathrm{~mm}$, they represent also joints having $l=50 \mathrm{~mm}$.

As it easy to predict, the tensile strength of a bolted joint is instead strictly related to the actual value of the bolt tightening torque. Consequently, tensile tests of various specimens were preliminarly carried out by varying this important parameter. As it is possible to observe from Fig. 5, such experiments have shown that in practice the tensile failure load $\left(P_{\max }\right)$ of a simply bolted Al-GFRP double-lap joint is a non-monotonic function of the tightening torque: the failure load increases until a tightening torque of about $14 \mathrm{Nm}$, then it decreases due to the damaging of the GFRP adherent produced by the high surface compression applied by the bolt.

From Fig. 6, that shows the load-displacement curves of simply bolted joints with tightening torque $T_{t}=8 \mathrm{Nm}$ (value recommended by the bolt manufacturer) and $T_{t}=14 \mathrm{Nm}$ (value that maximizes the tensile strength of the joint), it is possible to observe how the tensile behavior is represented by a first "elastic" phase,

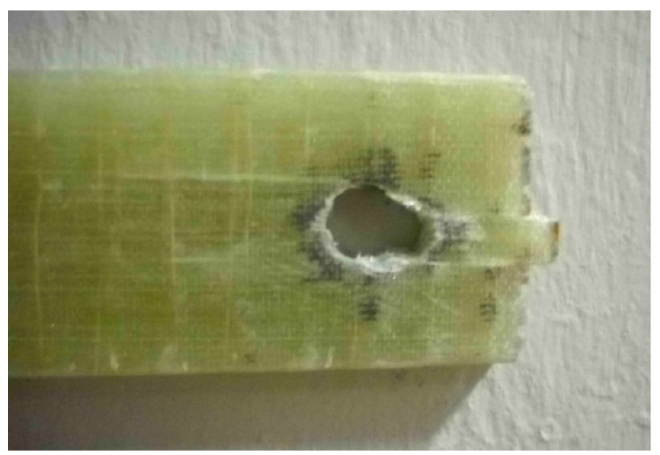

(a)

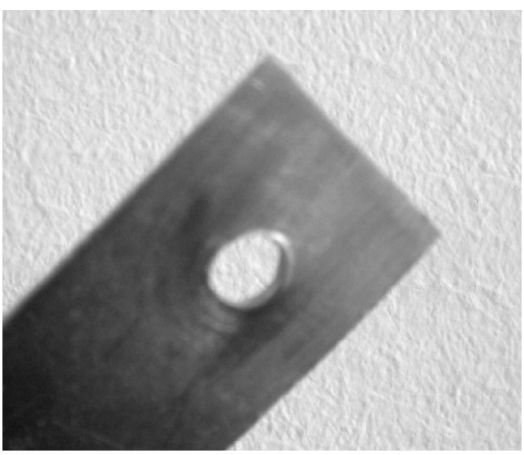

(b)

Fig. 7. Typical damage of the examined Al-GFRP double lap bolted joint: (a) shear failure of GFRP adherent lip and (b) hole ovalization of aluminum component. 


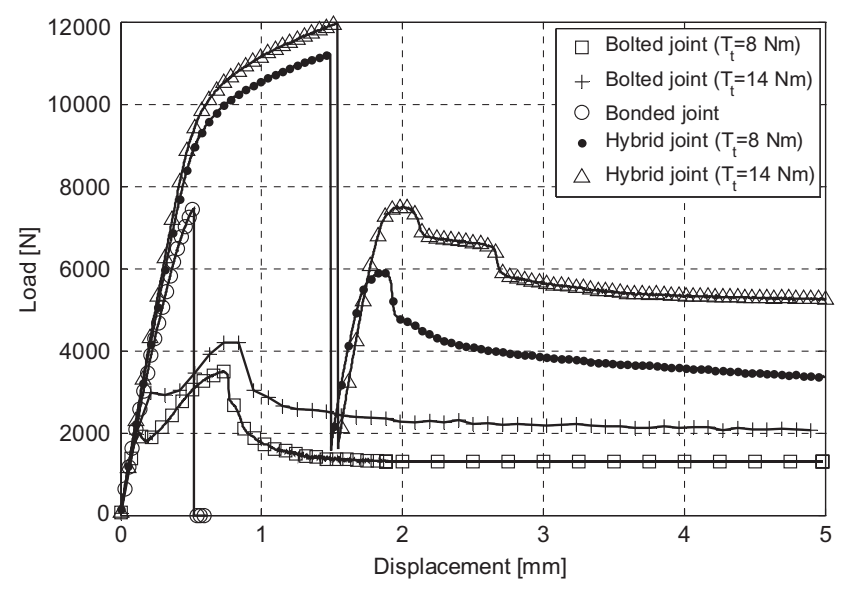

Fig. 8a. Load-displacement curves for Al-GFRP joints with overlap length $l=25 \mathrm{~mm}$.

in which the load is transmitted by the Al-GFRP static friction produced by the bolt axial pre-load, followed by a second "sliding" phase characterized by the Al-GFRP dynamic friction under a quasi-constant load; it follows a third "almost linear" phase, in which the load is partially transmitted by the Al-GFRP friction and by the shear stresses of the bolt. Such an important phase stops when the maximum load is reached, and is followed by a fourth and final phase characterized by a progressive shear failure of the lip of the GFRP laminate (see Fig. 7(a)) which corresponds to the complete failure of the joint. The examination of the joint after failure shows, in fact, that the two aluminum components are subjected only to a limited hole ovalization (see Fig. 7(b)).

In terms of tensile strength, the experimental tests have shown that the increasing of the bolt tightening torque from $T_{t}=8 \mathrm{Nm}$ to $T_{t}=14 \mathrm{Nm}$, leads not only to the increase of the maximum tensile load of about $25 \%$ (from $P_{\max }=3465 \mathrm{~N}$ to $P_{\max }=4255 \mathrm{~N}$ ), but also to a comparable increase of the energy absorption (from $E_{a}=9.12 \mathrm{~J}$ to $\left.E_{a}=11.9 \mathrm{~J}\right)$.

Finally, the comparison between such results and those of the simply adhesively bonded joint reported in the previous chapter, shows that the examined Al-GFRP double-lap joints obey to the general rule that the simply bonded joints between composites or composite and metal, exhibit a tensile strength higher than that of simply bolted joints, but a lower damage tolerance.

In detail, for the examined case the tensile strength of the simply adhesively bonding joint is about 2-3 times that of the simply bolted ones; on the contrary, the energy absorption of the simply bonded joints is only about $20-40 \%$ of that of the simply bolted joints.

\subsubsection{HBB joints}

Fig. 8 a shows the characteristic tensile curve relative to the HBB joints, having overlap length $l=l_{\min }=25 \mathrm{~mm}$ and subjected to $T_{t}=8$ and $14 \mathrm{Nm}$. In order to compare their behavior with that of the corresponding simply bolted and simply bonded joints, the relative load-displacement curves, already reported in Figs. 4 and 6, have been reported in the same figure. It is seen how the HBB joints exhibit a first elastic phase that is more wide than that of the simply bonded joints; in fact, it stops at a strain level that in practice coincides with the failure strain of the simply adhesively bonded joints. This confirms the beneficial effects of the compression due to the bolt, that leads to a decreasing of the maximum peeling and shear stresses at the joint free edge, as well as to the simultaneous increasing of the shear stresses near the bolt due to the partial load transmission through the bolt itself. In other words, as it is confirmed by the successive numerical simulations, the bolt leads to more uniform stress distributions along the overlap with a

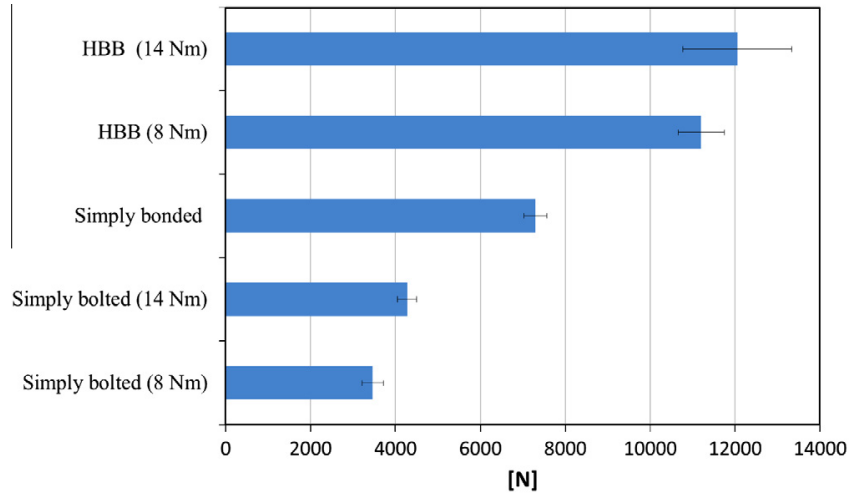

Fig. 8b. Maximum load of the various joints examined, with overlap length $l=25 \mathrm{~mm}$.

consequent significant increasing of the maximum load that corresponds to the initiation of the adhesive brittle failure. In particular, from Fig. 8a the it is seen how the load corresponding to the end of the elastic phase of the HBB joints is about 30\% higher than that of the simply adhesively bonded joint, and is associated with a higher stiffness (about $+35 \%$ ) that confirm how also at relative low strain levels a significant load portion is transmitted by the bolt. However, in this first elastic phase, the different tightening torque value does not lead to significant differences in the joint behavior (the relative curves are quite coincident - see Fig. 8a).

A successive elasto-plastic phase follows the linear one, until the maximum load is reached; such a phase is characterized by the plasticity of the aluminum adherents (the tensile stress is higher than the yielding stress), as well as by a significant shear strain of the adhesive, higher than that is supported by the same adhesive in the simply adhesively bonding joint but without failure, due to the beneficial compression effects of the bolt tightening, that are stronger in the case of $T_{t}=14 \mathrm{Nm}$ that lead to a maximum load about $10 \%$ higher than that corresponding to $T_{t}=8 \mathrm{Nm}$.

Due to these beneficial effects, the absolute maximum load is $60-70 \%$ higher than that of the simply adhesively bonded joint.

At the absolute maximum load follows a significant load dropping of about $85 \%$; such a phase corresponds to the brittle adhesive failure with a consequent further load transfer to the bolt; the load dropping, in fact, is followed by a new load increase until a local maximum load that, for both the examined bolt tightening values, is about $75 \%$ higher than the failure load of the corresponding simply bolted joints. In accordance with the experimental evidence, this important fact, that contributes significantly to the damage tolerance of the $H B B$ joints, can be explained by considering that the beneficial compression effects of the bolt prevent the adhesive failure in the annular zone near the bolt, so that the adhesive continues to give a significant contribution to the load transmission.

Such a second local maximum is then followed by a final phase characterized by a slightly decreasing load, that tends in practice to the ultimate load value of the corresponding simply bolted joint. As it has been observed experimentally, this phase is associated with the complete adhesive failure and the shear failure of the GFRP laminate lip, which corresponds the final failure of the joints. In practice, it is possible to state that the HBB joints with $l=l_{\min }$ are characterized by a complex damaging process which is the sequence of the failure mechanisms of the adhesively bonded joint and of the bolted joint, i.e. adhesive failure at the interface between adhesive and aluminum, followed by shear failure of the lip of the GFRP adherent.

The main results for the examined joints (having $l=l_{\min }$ ) in terms of maximum load and energy absorption, are synthetically reported in Figs. 8b and 8c. From Fig. 8b it is seen immediately how the examined HBB joints have in practice a tensile strength 


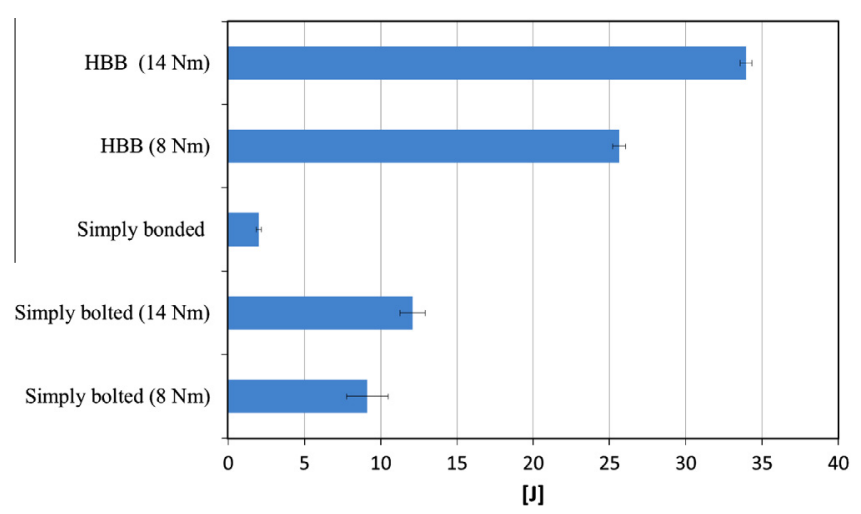

Fig. 8c. Energy absorption of the various joints examined, with overlap length $l=25 \mathrm{~mm}$.

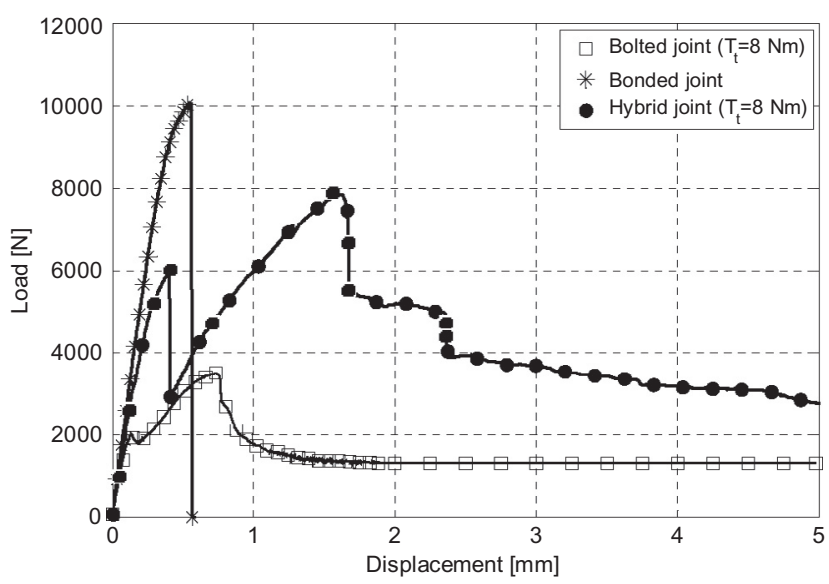

Fig. 9. Load-displacement curves for Al-GFRP joints with overlap length $l=50 \mathrm{~mm}$.

that is the sum of that of the simply bonded joint and of the simply bolted joint. Consequently, if a load efficiency $e_{L}$ of a HBB joint is defined as the ratio between its maximum load $\left(P_{\max , \text { Нвв }}\right)$ and the sum of those relative to the simply adhesively bonded $\left(P_{\text {max,bonding }}\right)$ and simply bolted joints $\left(P_{\max , \text { bolted }}\right)$, i.e.:

$e_{l}=100-\frac{P_{\max , \text { HBB }}}{P_{\max , \text { bonding }}+P_{\max , \text { bolted }}}$

then it is possible to state that for the coupled material considered, the $H B B$ joints with $l=l_{\min }$ exhibit a load efficiency of $100 \%$.

Even higher is their efficiency in terms of energy absorption $E_{a}$; in fact, the comparison of the energy absorption of the $H B B$ joints with those of the corresponding simply adhesively bonded and simply bolted joint, shows a significant synergy (see Fig. 8c): the $E_{a}$ values of the $H B B$ joints are higher than twice the sum of the values corresponding to the simply adhesively bonded one and the simply bolted one.

On the contrary, similar results are not observed experimentally for the HBB joint with $l=2 l_{\text {min }}=50 \mathrm{~mm}$ commonly used in practical applications, as it is possible to see from Fig. 9 that show the load-displacement curves relative to this case. It is seen, in fact, how in this case the presence of the bolt in the HBB joint does not lead to the beneficial effects observed in the previous case, i.e. the increase of the maximum load. As it is easy to understand, in this case the bolt is located in the central region of the bonded surface, far from the adhesive free edges, so that it cannot lead to the beneficial decrease of the maximum stresses, but it leads only to a weakening of the joint due to the hole presence, with a consequential decrease of the maximum load. In more detail, due to this

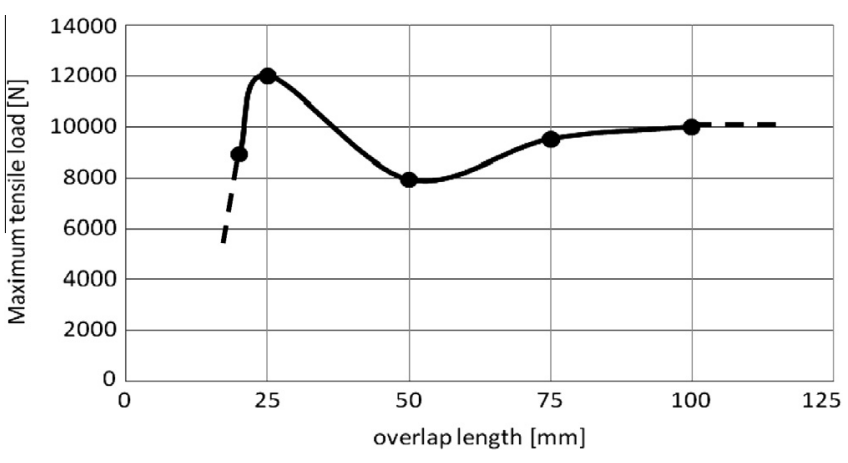

Fig. 10. Maximum tensile load of HBB joints vs. the overlap length.

weakening, the HBB joint exhibits a first linear phase that stops with the premature partial failure of the adhesive, that occurs at a load level lower than that of the simply adhesively bonded joint (see Fig. 9); it follows a relative load dropping of about 50\%, with a final load that in practice coincides with that supported only by the bolt at this strain level. In this condition, in fact, the adhesive zones that support the most load are fully damaged, whereas the central zone of the adhesive gives only a little contribution to the load transmission because, as it is well known from theory [15-18], it is subjected to relatively low stresses.

The load dropping is follows by a new load increase until the absolute maximum load, that is about $80 \%$ the maximum load of the simply adhesively bonded joint; in such a phase the applied load is divided between the non damaged adhesive and the bolt. The absolute maximum load is followed by a final phase characterized by a decreasing load up to the joint failure.

Synthetically, the experimental results clearly show that, due to the premature partial damage of the adhesive, the HBB joint with overlap length $l=2 l_{\min }$, exhibits a tensile strength lower than that of the simply adhesively bonded joint.

It is important to note that the HBB joint configuration with $l=2 l_{\min }$ obeys the rule indicated in [13] that the strength of an hybrid joint can be higher than that of the simply bonded joint only if the simply bolted joint have a strength higher than this last, whereas it is not true for the $H B B$ joint configuration with $l=l_{\text {min }}$ properly chosen in the present study.

In other words, it is possible to state that the above mentioned rule is not a general rule because, as shown by the above reported experimental analysis, the use of the overlap length $l=l_{\min }$ allows the user to obtain $H B B$ joints characterized not only by an improvement of the damage tolerance (i.e. of the energy absorption), but also by a significant increase of the static tensile strength.

Also, further tensile tests performed on HBB joints having $l=20 \mathrm{~mm}\left(l<l_{\min }\right)$ and $l=75 \mathrm{~mm}\left(l>2 l_{\min }\right)$, have synthetically shown that (see also Fig. 10):

(1) if $l<l_{\min }$ the tensile strength decays abruptly, due to the strong reduction of the surface of the adhesive and the consequential significant increase of the maximum stresses in the adhesive layer;

(2) if $l>2 l_{\min }$ the tensile strength increase with $l$ and tends to the value of the simply adhesively bonded joint when $l$ diverges; in this cases in fact the beneficial effect of the bolt are always negligible, whereas the relative weakening of the joint due to the bolt insertion, decrease when $l$ increase.

Therefore, as it is clearly shown from Fig. 10, the optimal overlap length of the examined joint corresponds in practice with its minimum length provided from theory [6,15-18], i.e. from Eq. (1).

Finally, as a practical general rule it is possible to said that an efficient HBB joint cannot be obtained by the simple insertion of 
a bolt into a common simply adhesively bonding joint (having $l \geqslant 2 l_{\min }$ ), but a prior reduction of the overlap length to the corresponding minimum value is necessary to this scope.

\subsection{Fatigue tests}

In many practical applications the joints can be subjected to relevant fatigue loads; interesting works on the fatigue behavior of bonded joints have been carried out by Crocombe et al. by considering also the effects of the mean load $[28,29]$ and the load ratio $[30,29]$, as well as the possibility to evaluate the failure load by means of the so called Coesive Zone Model (CZM).

In order to assess if the HBB joints with $l=l_{\min }$ exhibit also a good fatigue behavior, a systematic fatigue analysis has been performed by considering also the corresponding simply adhesively bonded joints and the simply bolted joints.

The fatigue tests have been carried out by using the same material testing machine MTS 810 with a $100 \mathrm{kN}$ load cell, already used for the static tests. For each joint examined, the tests were performed at different percentages values $\left(P_{\%}\right)$ of the maximum static load $\left(P_{\max }\right)$. In all the tests the ratio $(R)$ between the minimum and maximum load has been set equal to 0.1 (tensile-tensile fatigue) with a load frequency of $10 \mathrm{~Hz}$. By appropriate temperature measurements, it has been proved that such a load frequency does not lead to a significant increase of the joint temperature, that could give significant decays of the fatigue strength.

Like static analysis, the experimental tests have been performed first on the simply adhesively bonded and simply bolted joins, then on the studied HBB joints.

\subsubsection{Simply adhesively bonded joints}

In order to analyze in detail the damaging process during the fatigue tests, as well as to detect how the total fatigue life divided between defect nucleation and crack propagation, the amplitude of the crosshead displacement $\Delta d=\left(d_{\max }-d_{\min }\right)$ vs. the number $N$ of fatigue cycles, has been plotted in proper graphs. In detail, Fig. 11 shows such a curves relative to the simply adhesively bonded, for various values of the load percentage $P_{\%}$.

Taking into account that under a constant fatigue load the nucleation of a defect is characterized by a constant displacement amplitude, whereas the successive phase of crack propagation is characterized by an increasing displacement amplitude, from Fig. 11 it is possible to observe how, in accordance with the experimental evidence, the most of fatigue life is spent for the crack propagation. In detail, the time spends for the nucleation is about $20-25 \%$ the fatigue life, the remaining $75 \%$ is spent for the crack propagation.

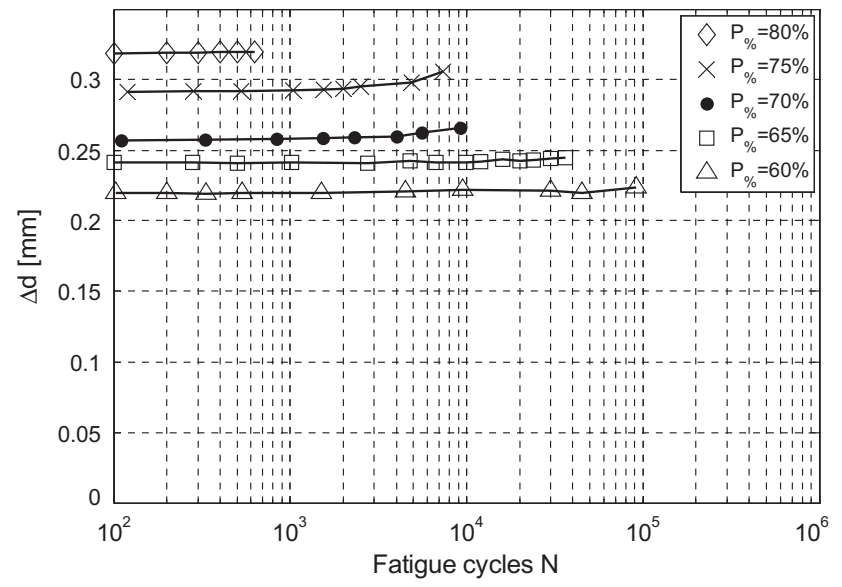

Fig. 11. $\Delta d-N$ curves of simply adhesively bonded joint, for various percentage load $P_{\%}$.
The fatigue tests have also shown that, like the static case, the crack starts always from the attach edge of the GFRP adherent (point A in Fig. 1) and propagates at the interface between adhesive and aluminum, toward the attach edge of the aluminum adherents (point B in Fig. 3).

Moreover, all the simply adhesively bonded joints examined, have exhibited a good fatigue strength, with a ratio between fatigue strength and static strength (fatigue ratio) of about 0.5 .

\subsubsection{Simply bolted joints}

The fatigue tests has been performed on simply bolted joint subjected to a tightening torque $T_{t}=14 \mathrm{Nm}$, which corresponds the maximum static tensile strength, and the relative $\Delta d-N$ curves are reported in Fig. 12. From this figure it is possible to observe that the analyzed simply bolted joint have a very high fatigue strength with a fatigue ratio of about 0.8 . The constant value of the displacement amplitude for about all the fatigue test indicates that most the fatigue cycles are spent for the nucleation of the crack, which propagates quickly until the final failure of the joint. The experimental tests have also shown that, like the static case, the fatigue failure of the simply bolted joints is due to the shear failure of the lip of the GFRP component.

\subsubsection{HBB joints}

In order to detect the effects of the bolt tightening torque on the fatigue behavior of the HBB joint, the fatigue tests have been performed by considering $T_{t}=8$ and $14 \mathrm{Nm}$, and the results have been reported in Fig. 13(a) and (b). From these figures it is possible to observe that, for all the percentage load levels applied, the most of fatigue life of HBB joints is spent for the crack propagation. In detail, the experimental evidence shows that in practice the crack propagation starts from both the free edges and then propagates toward the central zone of the joint; however, the final joint failure follows always the failure of the lip of the GFRP adherent, that occurs abruptly when the crack reaches the bolt zone; this fact occurs for all the applied percentage load that corresponds to a finite life $\left(N \leqslant 10^{6}\right)$, because the fatigue strength of both the examined joint is always higher than the failure load of the simply bolted joint.

\subsubsection{Results comparison}

In order to evaluate the actual mechanical efficiency of the examined HBB joints in the presence of fatigue loads, Fig. 14 shows the relative Wöhler curves along with those of the simply bolted and simply adhesively bonded joints.

From this figure, it is observed immediately that the fatigue strength of the $H B B$ joints is significantly higher than that of

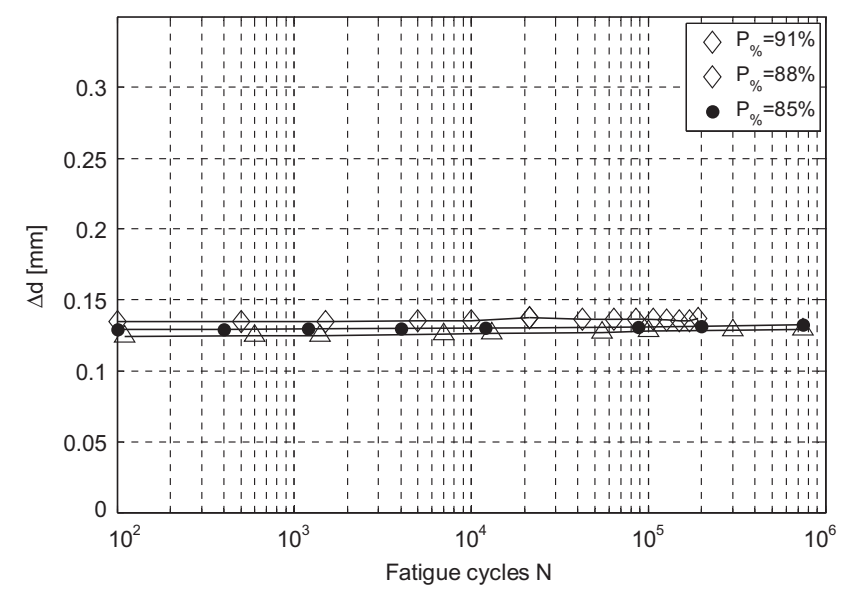

Fig. 12. $\Delta d-N$ curves for simply bolted joints with $T_{t}=14 \mathrm{Nm}$. 


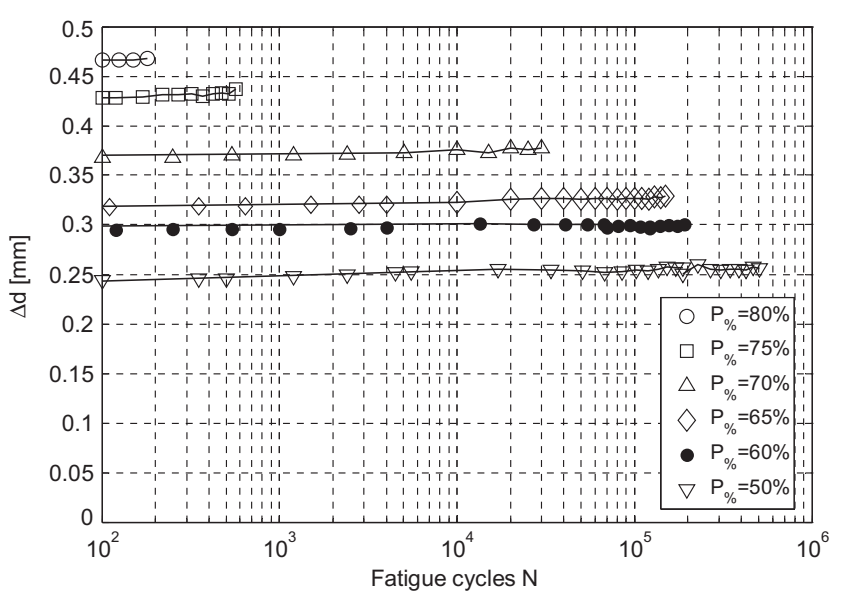

(a)

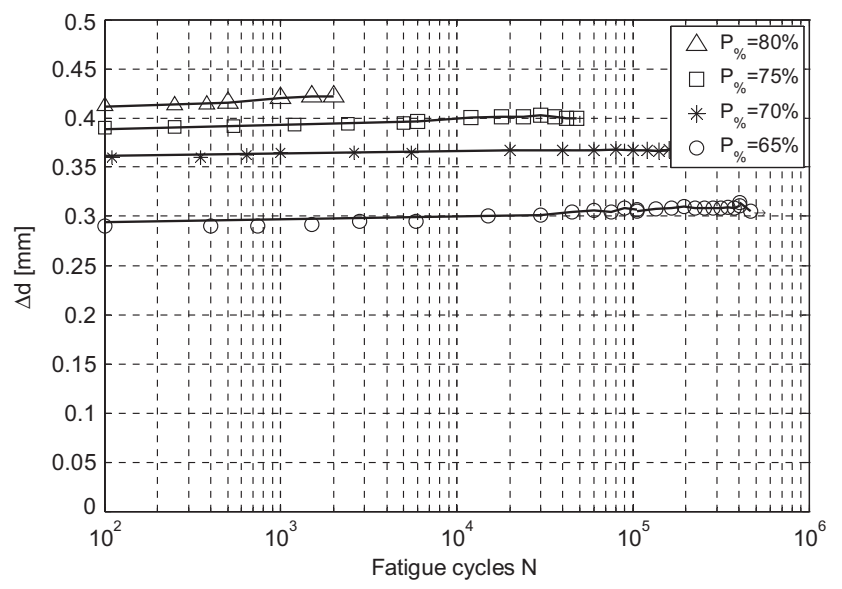

(b)

Fig. 13. $\Delta d-N$ curves of $H B B$ joints with bolt tightening torque equal to: (a) $8 \mathrm{Nm}$ and (b) $14 \mathrm{Nm}$, for various percentage load $P_{\%}$.

the corresponding simply adhesively bonded joints which, in turn, is higher than that of the simply bolted joints. From this figure it is seen how moving from $T_{t}=8$ to $T_{t}=14 \mathrm{Nm}$ the fatigue strength increases significantly of about 20-25\%; such an effect is therefore comparable with that observed in the static case (see Fig. 6).

In terms of fatigue life, respect to the simply adhesively joint the improvements are very high: moving from a simply adhesively bonded joint to the HBB joint, in fact, the fatigue life increases of about 4-5 order of magnitude. As an example, for a fatigue load of $6500 \mathrm{~N}$ the fatigue life increases from about $10^{2}$ cycles for the simply adhesively bonded joints, to over $10^{6}$ cycles for the HBB joint with $T_{t}=8 \mathrm{Nm}$ (over $10^{7}$ cycles can be estimated by extrapolating the $T_{t}=14 \mathrm{Nm}$ Wohler curve).

Also in terms of high cycles fatigue strength $\left(N \geqslant 10^{6}\right)$ the improvement is very high. From Fig. 14 it is see how moving from the simply adhesively bonded joint to the HBB joints, the fatigue load passes from about $3000 \mathrm{~N}$ to over $6000 \mathrm{~N}(+100 \%$ about) for $T_{t}=8 \mathrm{Nm}$, and over $8000 \mathrm{~N}$ for $T_{t}=14 \mathrm{Nm}(+150 \%$ about $)$.

\section{Numerical analysis}

In order to better understand the behavior of the optimized HBB joint respect to the corresponding simply adhesively bonded joint, proper 3D numerical simulations of both the joints have been

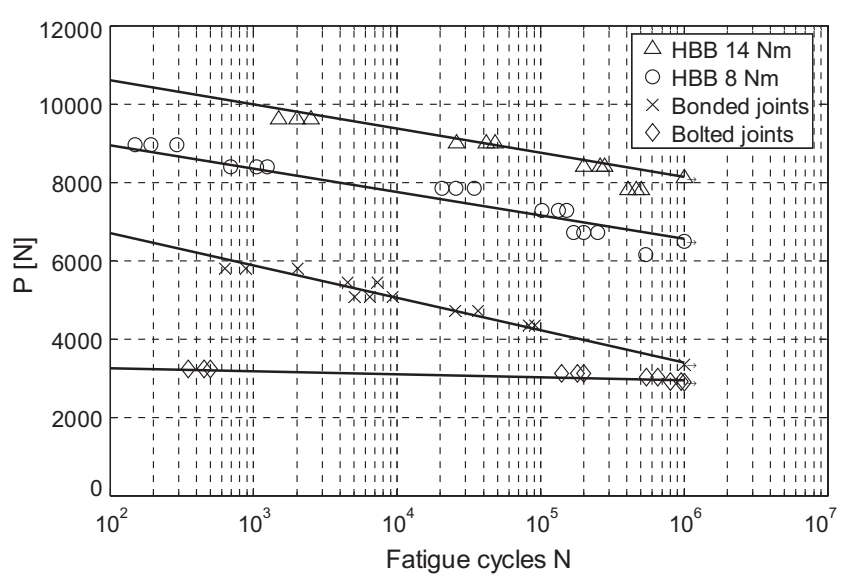

Fig. 14. Wöhler curves of the optimized Al-GFRP examined joints.

performed by using the ANSYS code. In particular, taking into account the main damage mechanism detected by the previous experimental analyses, i.e. the progressive adhesive failure at the adhesive-aluminum interface, the distribution of the shear and peel stresses at such an interface has been analyzed in detail.

Exploiting the two planes of symmetry of the examined doublelap joints, the numerical model reproduces only $1 / 4$ of the joints; they are constituted by 3D brick elements whose dimension and distribution have been optimized by a simple convergence test (see Fig. 15). Obviously, a particular mesh refinement has been used at the two free edges where, as it is well known from theory [15-18], significant stress concentrations occur. Moreover, in order to permit an easy comparison of the stress in the two models, the same tensile load of $7250 \mathrm{~N}$ (the failure load of the simply adhesively bonded joint) has been applied. Finally, taking into account that both the adhesive and the composite have a linear behavior, as well as that for the low applied load the aluminum adherent remains always in the elastic field, a simple elastic material model have been used for all the materials.

\subsection{Adhesively bonded joints}

Fig. 16 shows the shear and the peel stress distribution at the interface between adhesive and the aluminum adherent, from the attach edge of the aluminum adherent (point $B$ ) to the attach edges of the GFRP adherent (point A); in particular, to highlight the effects of the different stress state at the outer edges (plane stress state) and at the centerline region (plane strain state), both the distributions are reported in Fig. 16.

First, in accordance with the theory [6,15-18], Fig. 16(a) shows the shear stress imbalance, with higher shear stress values at the attach edge of the GFRP internal adherent (point A). Also, the simulations show that the shear stress distribution along the centerline is always higher than that along outer edge (up to about $+25 \%$ ).

Concerning the peel stresses, instead, the simulations show (see Fig. 14(b)) that detrimental peel stresses occurs near the attach edge of the GFRP adherent (point A), where there are also the maximum shear stresses. Therefore, in accordance with the experimental evidence, both the numerical stress distributions confirm that the most stressed free edge is the attach one of the GFRP adherent (A), from which the interface cracks propagate until the full failure of the simply adhesively bonded joint. In more detail, it is seen that for a joint with a finite width the most stressed point is the outer point of the attach edge of the GFRP. Consequently, an accurate evaluation of the tensile strength of such joints should consider 


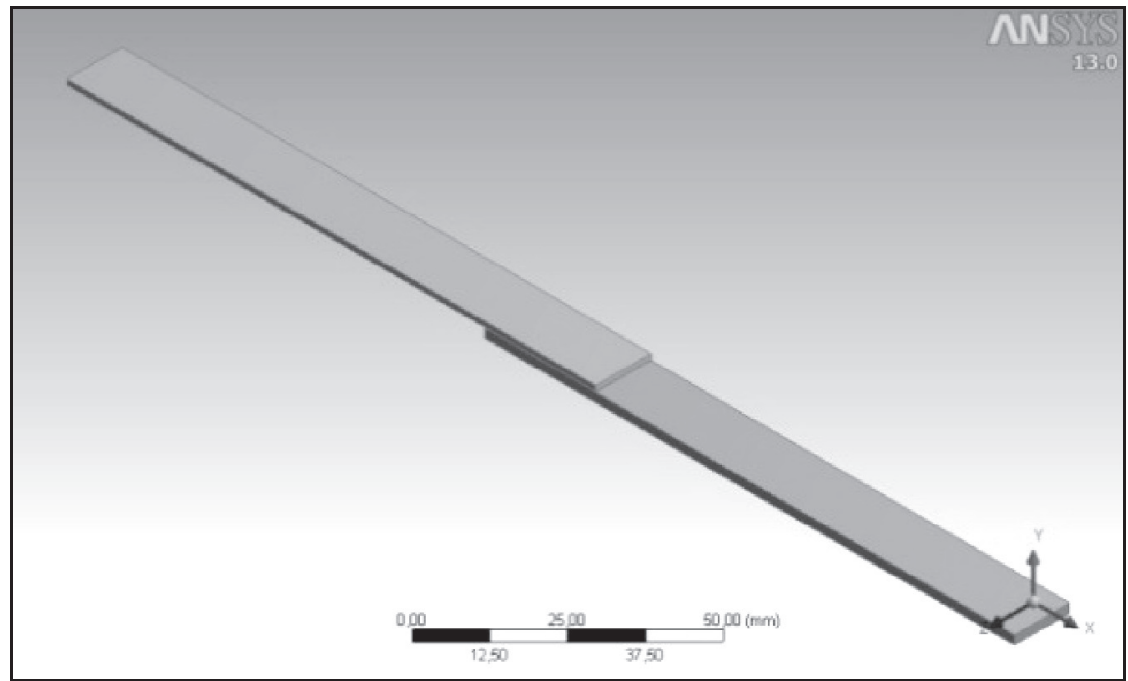

(a)

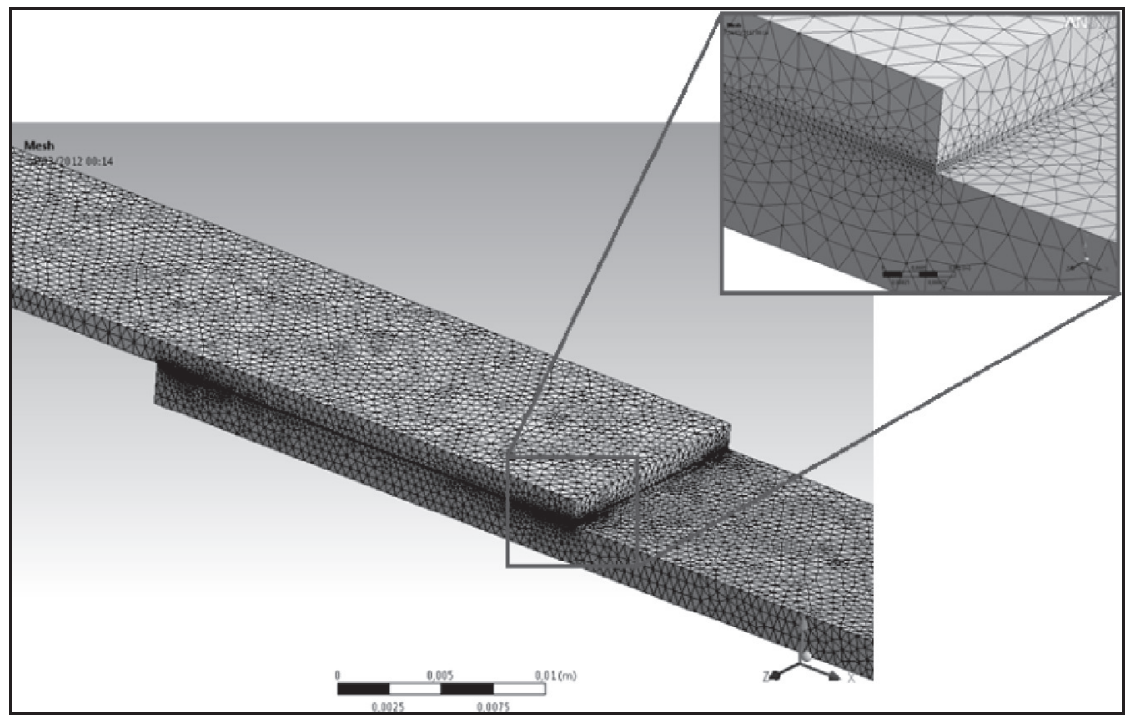

(b)

Fig. 15. Numerical simulations of the simply adhesively bonded joint: (a) 3D FEM model and (b) refined mesh at the free edges.

the interlaminar stresses in this particular point, combined with an appropriate failure criterion as the point or the average stress criterion [31,32] or proper criterions based on GSIFs [22].

\subsection{Hybrid joints}

Fig. 17 shown the finite element model used to simulate the HBB joints; as above, the double symmetry has allowed to reduce the model to $1 / 4$ the actual joint. The contact between the bolt and the adherents has been simulated by using a proper contact/target algorithm with a friction coefficient equal to 0.2. Also, an axial load of $7 \mathrm{kN}$ has been applied to the bolt to simulate the actual bolt tightening, whereas a slight hole/bolt radial clearance of $0.1 \mathrm{~mm}$ has been simulated by using a hole diameter of $6.1 \mathrm{~mm}$.

In Fig. 18(a) and (b), the shear and the peel stress distributions along the centerline and the outer edge of the studied $H B B$ joint, have been reported respectively. It possible to note first that, the maximum stresses are very lower than those observed from the numerical simulations of the simply adhesively bonded joint, although the A free edge (attach edge of the GFRP adherent) remains that one subjected to the maximum stresses. In more detail, as it can be better observed from Fig. 19, that shows the comparison between the shear stresses of the HBB and the simply adhesively bonded joint, the insertion of a bolt in a simple adhesively bonded joint leads to more than an halving of the maximum shear stresses (from over $25 \mathrm{MPa}$ to about 11-12 MPa), and similar effects are observed in both the centerline (Fig. 19(a)) as in the outer edge (Fig. 19(b)). Higher beneficial effects are also observed into the peel stresses, as it is seen clearly from Fig. 20; in this case, in fact, the peel stresses are reduced to about a quarter at the centerline (Fig. 20(a)), to about one-tenth at the outer edge (Fig. 20(b)).

These significant reductions of the maximum stresses, corroborate widely the increasing of about $60-70 \%$ of the tensile strength of the HBB joint with respect to the simply adhesively joint, as previously detected experimentally. Obviously, the only knowledge of such maximum stresses is not sufficient for an accurate numerical prediction of the tensile strength of the HBB joint because, as it is 


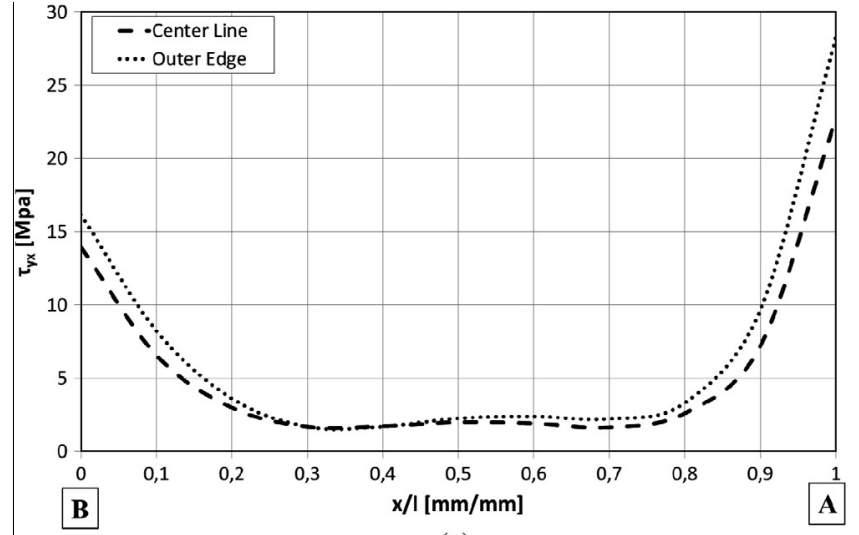

(a)

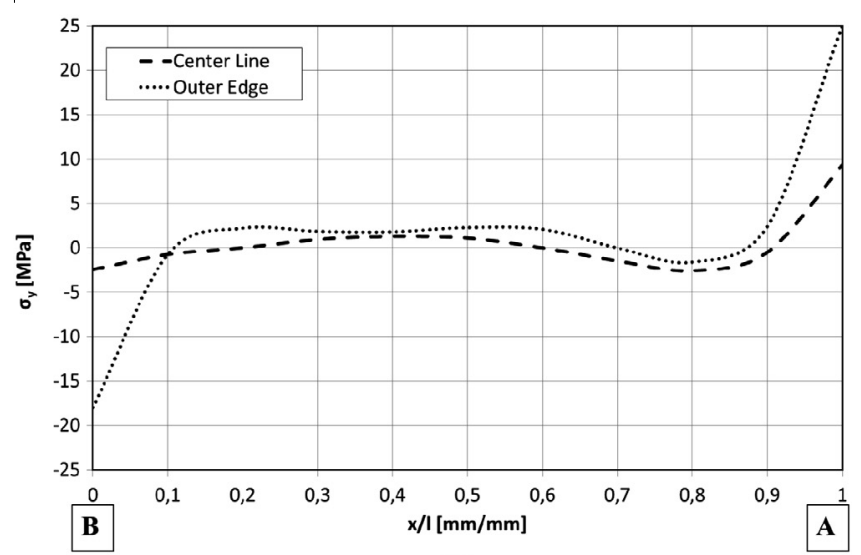

(b)

Fig. 16. Numerical simulations: (a) shear stresses distributions and (b) peel stresses distributions for the simply adhesively bonded joints examined.

well known in literature, a reliable strength prediction of a components made by PMCs and subject to significant stress concentrations, can be obtained only from accurate experimental analyses [33] or by theoretical approaches that take into account the stress concentration sensitivity [31,32] and the possible residual stresses [34].

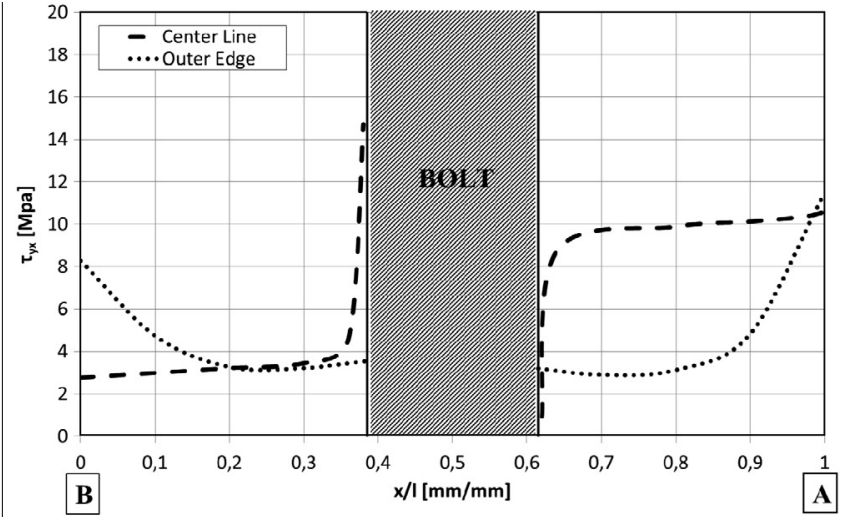

(a)

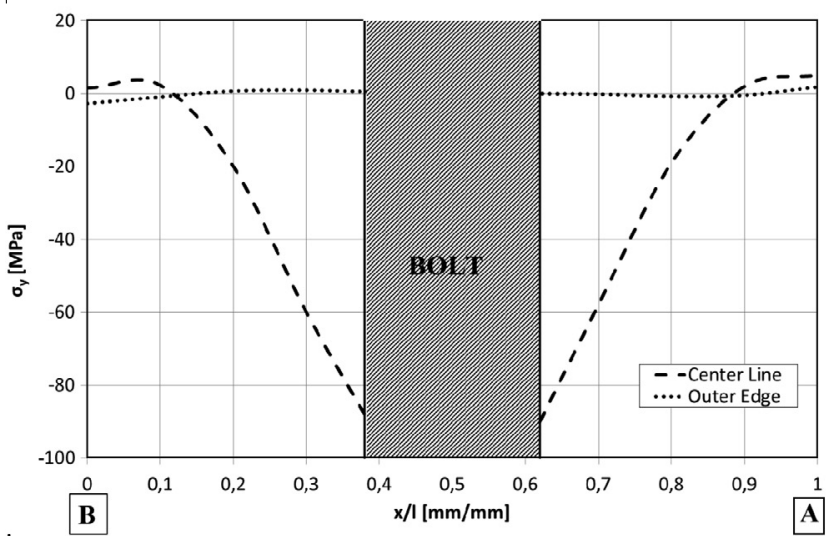

(b)

Fig. 18. Numerical simulations: (a) shear stresses distributions and (b) peel stresses distributions for the $H B B$ joint examined.

Finally, although the correlation between fatigue life and stress distribution is in general a very complex task, it is certainly possible to state that the observed stresses reduction is responsible also of the significant increase of the fatigue strength of the $H B B$ joint with respect to that of the simply adhesively bonded joint.

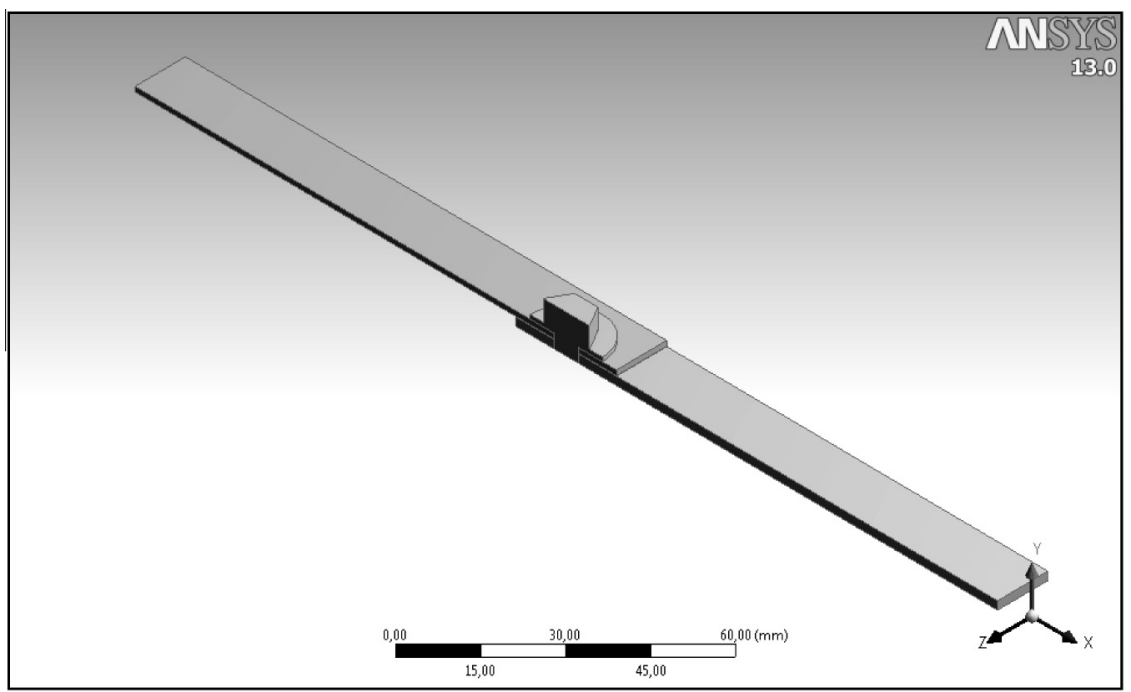

Fig. 17. 3D finite element model of the $H B B$ joints examined. 


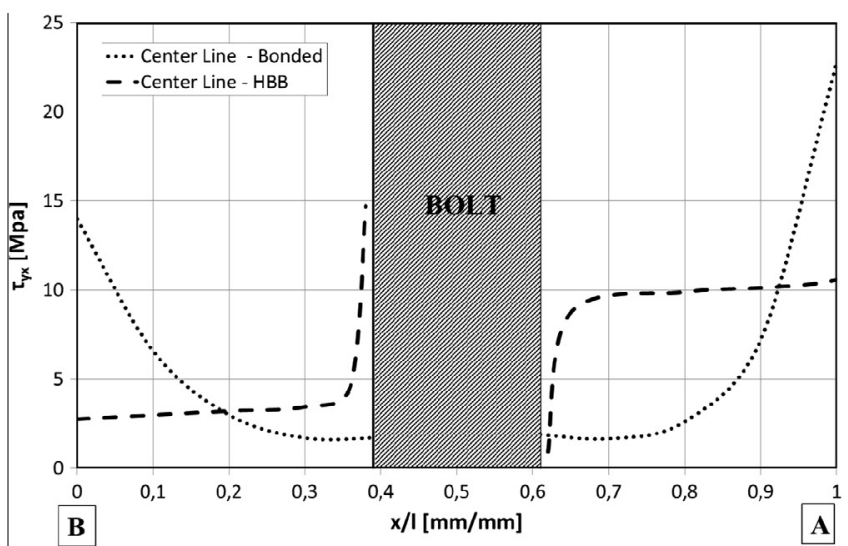

(a)

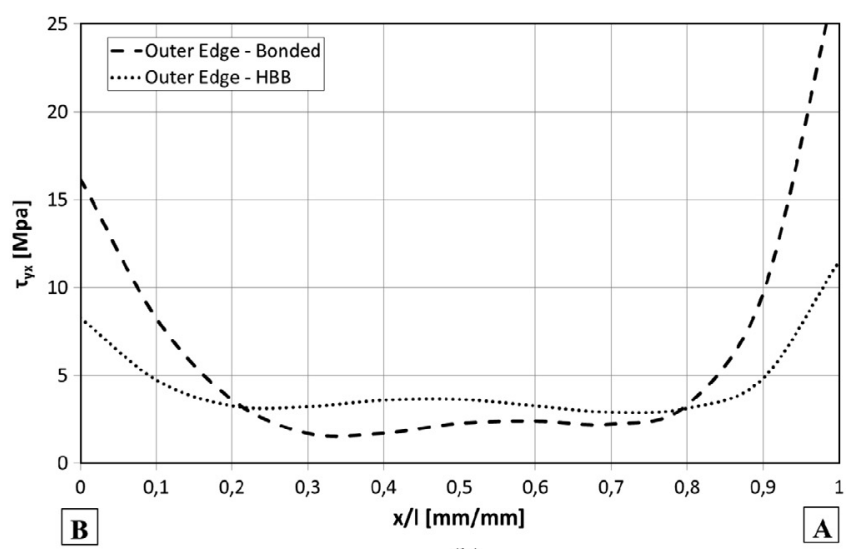

(b)

Fig. 19. Numerical simulations: comparison between the shear stresses for the $H B B$ joint and the simply adhesively bonded joint at the (a) centerline and the (b) outer edge.

\section{Conclusions}

By analyzing experimentally HBB joints with different overlap length, it has been shown that respect to the simply bonded joints, the HBB joints can exhibit not only a higher damage tolerance, i.e. a higher energy absorption, but also a significant higher static strength if the overlap length $l$ is set equal to the so called "minimum length" $l_{\text {min }}$, provided from theory. By using such a geometrical optimized configuration, in fact, the beneficial compression effects of the bolt, give rise to a significant decrease of the maximum shear and peel stresses that develop the free edges of the adhesive layer, with a consequential significant increasing of the mechanical performance (up to $+60-70 \%$ ). In detail, the tensile strength of the HBB is in practice equal to the sum of the tensile strength of simply adhesively bonded and bolted joints (efficiency $100 \%)$.

Therefore, unlike it is widely done in aeronautical/aerospace field, the use of higher overlap length have to be avoided because, as proved experimentally, in this condition the addition of bolts to a simply adhesively bonded joint, leads only to a weakening of the joint, with a significant decrease of the static strength (over $-20 \%$ ).

The study has also shown that the static strength of optimized HBB joints, i.e. with $l=l_{\min }$, is maximized (up to about $+10 \%$ ) by the use of the maximum bolt tightening torque that does not lead to a GFRP surface damage caused by the bolt compression.

Moreover, in term of energy absorption, the optimized HBB joint leads to a significant synergy; it is in fact characterized by an energy absorption more higher than the sum of the values

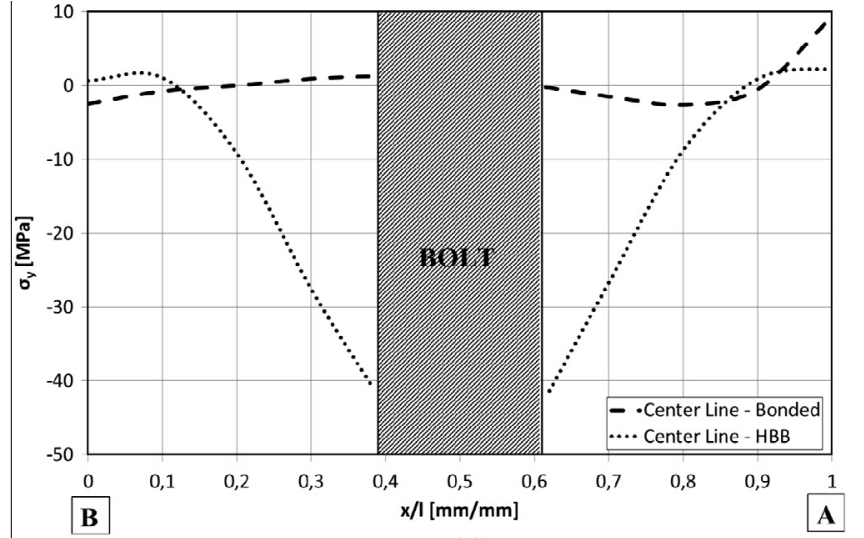

(a)

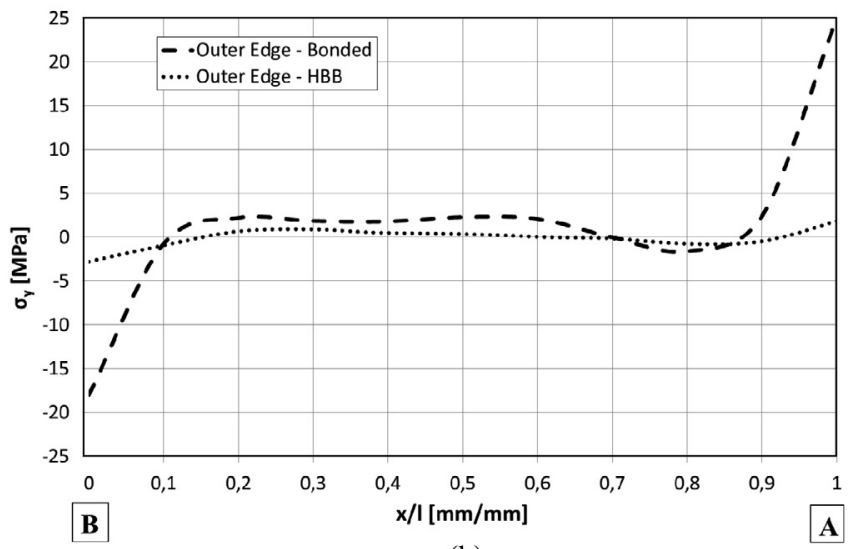

(b)

Fig. 20. Numerical simulations: comparison between the peel stresses for the $H B B$ joint and the simply adhesively bonded joint at the (a) centerline and at the (b) outer edge.

corresponding to the simply bolted joint and to the simply adhesively bonded joint.

Finally, although the correlation between fatigue life and stress distribution is in general a very complex task, it is certainly possible to state that the observed stresses reduction is responsible also of the significant increase of the fatigue strength of the $H B B$ joint with respect to that of the simply adhesively bonded joint.

Therefore, taking into account the strong relationship between energy absorption and damage tolerance, it is possible to state that the optimized HBB joints allow the user also to optimize the damage tolerance.

A systematic fatigue analysis carried on the optimized $H B B$ joints, as well as on the corresponding simply bolted and simply adhesively bonded joints, has corroborated that the fatigue life of such optimized HBB joints is significant higher than that of simply bonded joint that, in turn, is higher than that of the simply bolted joints. Moving from simply adhesively bonded joint to the $H B B$ joint, the fatigue life can increase up to about 4-5 order of magnitude.

In terms of high cycles fatigue strength, passing from the simply bolted or bonded joints to the $H B B$ joints, the fatigue strength increases up to about $+150 \%$ if the optimized bolt tightening torque is used.

Finally, the numerical simulations performed by using 3D models, have shown clearly that if the minimum overlap length is used, then the insertion of a bolt into a simply bonded joint, leads to more than an halving of the maximum shear stresses at the attach edges of the less stiff adherent, i.e. of the GFRP laminate. Higher 
beneficial effects are also produced into the maximum peel stresses, that are reduced to less than a quarter. Such beneficial effects fully justify the improvement of the performance of the optimized HBB joints in term of both static and fatigue strength.

\section{References}

[1] Reddy JR. Mechanics of laminated composite plates and shells: theory and analysis. CRC Press; 2004.

[2] Moroni F, Pirondi A, Kleiner F. Experimental analysis and comparison of the strength of simple and hybrid structural joints. Int J Adhes Adhes 2010;30:367-79.

[3] Kweon Jin-Hwe, Jung Jae-Woo, Kim Tae-Hwan, Choi Jin-Ho, Kim Dong-Hyun. Failure of carbon composite-to-aluminum joints with combined mechanical fastening and adhesive bonding. Compos Struct 2006;75:192-8.

[4] Kim Kwang-Soo, Yoo Jae-Seok, Yi Yeong-Moo, Kim Chun-Gon. Failure mode and strength of unidirectional composite single lap bonded joints. Compos Struct 2006:72:477-85.

[5] Owens JFP, Lee-Sullivan P. Stiffness behaviour due to fracture in adhesively bonded composite-to aluminum joints. Int J Adhes Adhes 2000;20:39-45.

[6] Hart-Smith LJ. Adhesive-bonding double-lap joints. NASA CR-112235; 1973.

[7] Choi Jin Ho, Lee Dai Gil. The torque transmission capabilities of the adhesively bonded tubular single lap joint and the double lap joint. J Adhes 1994:44:197-212.

[8] Kelly G. Load transfer in hybrid (bonded/bolted) composite single-lap joints. Compos Struct 2005;69:35-43.

[9] Fu Maofeng, Mallick PK. Fatigue of hybrid (adhesive/bolted) joints in SRIM composites. Int J Adhes Adhes 2001:21:145-59.

[10] Silva Lucas FM, Pirondi A, Öchsner A, editors. Hybrid adhesive joints. Heidelberg: Springer; 2011.

[11] Hart-Smith LJ. Design methodology for bonded-bolted composite joints. Technical Report AFWAL-TR-81-3154, Douglas Aircraft Company; 1982 [Hart-Smith LJ. Bonded-bolted composite joints. J Aircraft, 22, pp. 993-1000 (1985)].

[12] Hart-Smith LJ. Bonded-bolted composite joints. J Aircr 1985;22:993-1000.

[13] Maofeng Fu, Mallick PK. Fatigue of hybrid (adhesive/bolted) joints in SRIM. Int J Adhes Adhes 2001;21:145-59.

[14] Solmaz MY, Topkaya T. Progressive failure analysis in adhesively, riveted, and hybrid bonded double-lap joints. J Adhes 2013;89:822-36.

[15] Adams RD, Wake WC. Structural adhesive joints in engineering. Elsevier Applied Science Publishers; 1984
[16] Matthews FL. Joining fibre-reinforced plastics. Elsevier Applied Science Publishers; 1987.

[17] Hoskin BC, Baker AA. Composite materials for aircraft structures. AIAA education series; 1986.

[18] Heslehurst RB. Design and analysis of structural joints with composite materials. USA: DESTech Publications; 1986.

[19] ASTM D3528-96(2008). Standard test method for strength properties of double lap shear adhesive joints by tension loading.

[20] MATES - Technical Data Sheet: Epoxy Resin I-SX10.

[21] Karachalios EF, Adams RD, da Silva Lucas FM. Single lap joints loaded in tension with high strength steel adherends. Int J Adhes Adhes 2013;43:81-95.

[22] Russo A, Zuccarello B. Toward a design method for metal-composite co-cured joints based on the G-SIFs. Compos Part B Eng 2013;45(1):631-43.

[23] ASTM D3039/D3039M-08. Standard test method for tensile properties of polymer matrix composite materials.

[24] ASTM D4255/D4255M-01 (2007). Standard test method for in-plane shear properties of polymer matrix composite materials by the rail shear method.

[25] da Silva Lucas FM, Adams RD. Technique to reduce the peel stresses in adhesive joints with composites. Int J Adhes Adhes 2007;27:227-35.

[26] ASTM E8/E8M-11. Standard test methods for tension testing of metallic materials.

[27] Neto JABP, Campilho RDSG, Da Silva LFM. Parametric study of adhesive joints with composites. Int J Adhes Adhes 2012;37:96-101.

[28] Crocombe AD, Richardson G. Assessing stress state and mean load effects on fatigue response of adhesively bonded joints. Int J Adhes Adhes 1999;19: 19-27.

[29] Crocombe AD, Khoramishad H, Ashcroft, Katnam KB. A generalised damage model for constant amplitude fatigue loading of adhesively bonded joints. Int J Adhes 2010;30:513-21.

[30] Crocombe AD, Khoramishad H, Ashcroft, Katnam KB. Load ratio effect on the fatigue behaviour of adhesively bonded joints. J Adhes 2010;86:257-72.

[31] Whitney JM, Nuismer RJ. Stress fracture criteria for laminated composites containing stress concentrations. J Compos Mater 1974;8(3):253-65.

[32] Russo A, Zuccarello B. An accurate method to predict the stress concentration of composite laminates with circular hole and tensile loading. Mech Compos Mater 2007;43(4):359-76.

[33] Russo A, Zuccarello B. Experimental and numerical evaluation of the mechanical behaviour of GFRP sandwich panels. Compos Struct 2007;81: 575-86.

[34] Pagliaro P, Zuccarello B. Residual stress analysis of orthotropic materials by the through-hole drilling method. Exp Mech 2007;47:217-36. 